\title{
Thyroid Nodule Molecular Testing: Is It Ready for Prime Time?
}

\author{
Tahsin M. Khan and Martha A. Zeiger* \\ Surgical Oncology Program, National Cancer Institute, National Institutes of Health, Bethesda, MD, United States
}

Cytologically indeterminate thyroid nodules remain a diagnostic and clinical challenge, and molecular testing has been advocated and advanced as a diagnostic modality to help guide treatment. While studies have expounded on the improved diagnostic certainty with these tests, data demonstrating meaningful clinical impact and supporting their routine use is still limited at best. In this review, we discuss the limitations regarding diagnostic accuracy, impact on surgical decision-making and outcomes, and cost-effectiveness of molecular testing. By highlighting the limitations of these tests, we aim to promote more thoughtful utilization of these tools in the management of thyroid nodules going forward.

Keywords: indeterminate/suspicious thyroid nodule, thyroid cancer, molecular testing, diagnostic testing, management algorithm, thyroid surgery

\section{OPEN ACCESS}

Edited by:

Michele Caraglia,

University of Campania Luigi

Vanvitelli, Italy

Reviewed by:

Subramanian Kannan,

Narayana Health, India

Christian Albert Koch,

Fox Chase Cancer Center,

United States

*Correspondence:

Martha A. Zeiger

martha.zeiger@nih.gov

Specialty section:

This article was submitted to

Cancer Endocrinology,

a section of the journal

Frontiers in Endocrinology

Received: 31 July 2020

Accepted: 22 September 2020

Published: 09 October 2020

Citation:

Khan TM and Zeiger MA (2020)

Thyroid Nodule Molecular Testing:

Is it Ready for Prime Time?

Front. Endocrinol. 11:590128.

doi: 10.3389/fendo.2020.590128

\section{INTRODUCTION}

The incidence of thyroid cancer in the United States is rising exponentially, and thyroid nodules in particular are exceedingly common with prevalence rates of up to $70 \%$ in adults (1). Although most thyroid nodules (80-90\%) harbor benign pathology, the ability to detect malignancy and determine the appropriate course of treatment is of utmost clinical importance (1). The malignancy potential of a thyroid nodule is discerned in a multimodality fashion that includes clinical history, physical examination, radiographic assessments, and fine needle aspiration (FNA) biopsies (1-5). To this end, cytopathologic analysis of FNAs has emerged as a key adjunct to the clinical and radiologic criteria used to evaluate and characterize thyroid nodules. The Bethesda System for Reporting Thyroid Cytopathology (TBSRTC), developed by the National Cancer Institute in 2009 and revised in 2017 , is utilized widely to stratify risk of malignancy based on cytopathology and has been shown to accurately establish diagnosis (benign vs. malignant) in $70-80 \%$ of cases (6). Nevertheless, this still leaves $20-30 \%$ of FNA cases that fall under the Bethesda III, IV, and V categories of indeterminate or suspicious cytological results. Nodules in these categories have been shown to carry a wide range of malignancy rates ranging from 6 to $75 \%$ on final pathology (6). Given this wide variation in results for indeterminate and suspicious thyroid nodules, there has been a concerted effort in developing new technologies to more comprehensively characterize the malignant potential of thyroid nodules.

\section{MOLECULAR MARKER PANELS}

With recent advances in our understanding of the molecular underpinnings and genotypephenotype correlations in oncology, molecular testing has become frequently available and implemented in clinical practice for multiple cancer types. The fertile field of thyroid nodules is no exception. For instance, discovery of the oncogenic BRAF V600E mutation in high frequency 
(50-70\%) in papillary thyroid cancers and its associated implication for susceptibility to $B R A F$ targeted therapies have dramatically shifted the landscape of papillary thyroid cancer treatment (7). In addition to such single gene markers, the past decade has seen the development and marketing of commercial, multi-gene panel molecular tests that aim to improve diagnostic certainty in Bethesda III-IV indeterminate and suspicious nodules. Perhaps the most widely known of these are the Afirma Gene Expression Classified (GEC, since 2011) and ThyroSeq v2 (since 2014), which evaluates mRNA expression levels of 167 genes, or DNA mutations within a 19 gene panel, respectively (8). Both of these tests have been updated since their initial release to Afirma Genomic Sequencing Classifier (GSC, based on RNA sequencing technology evaluating 10,000 genes) and ThyroSeq v3 (next generation sequencing of 112 genes) (810). Additional commercial tests have included assays of oncogenic microRNA expression (e.g., ThyraMIR, Rosetta GX Reveal), and a seven-gene panel test for oncogenic point mutations and gene fusions (11-13). The ongoing evolution of these tests, combined with academic, clinical, and commercial interests, suggests that these molecular tests are now firmly part of the diagnostic armamentarium for thyroid nodules. Indeed, medical societal guidelines have continued to include discussion on molecular testing as diagnostic adjuncts for indeterminate thyroid nodules $(1-3,14-16)$.

Despite their widespread use, however, do these molecular tests truly impact clinical decision making and subsequent management of patients with indeterminate thyroid nodules? Or are a patient's history, cytology, and ultrasound findings enough to make sound clinical decisions? Herein we present a critical appraisal of the current state of adjunctive molecular tests used to differentiate benign from malignant nodules and, challenge their true clinical relevance in the context of diagnostic utility, influence on surgical decision-making, and cost effectiveness. We highlight evidence that suggests that the additional diagnostic certainty offered by these tests may be incremental at best from a clinical relevance perspective and that limitations persist pertaining to the real world application and influence on management decision vis a vis whether surgical intervention is pursued and if so what operation (17). By summarizing the true clinical impact of these tests and some of the associated pitfalls, we hope to promote future more reasoned and appropriate utilization of these tools in the management of indeterminate thyroid nodules.

\section{DIAGNOSTIC UTILITY}

The Bethesda classification categorizes FNA cytology into six different groups of varying malignant potential (6). Molecular testing is recommended only for "indeterminate or suspicious" nodules classified as "atypia of undetermined significance or follicular lesion of undetermined significance (AUS-FLUS)," "follicular neoplasm or suspicious for a follicular neoplasm (FN-SFN)," or "Suspicious for Malignancy (SFM)" categories. These classifications carry malignancy risk between 5 and 40\%, and the primary utilization of molecular testing has centered around obtaining a more definite assessment of this risk (6). Theoretically, any lesion deemed benign by molecular testing would be spared surgery and enter active surveillance pathways. Conversely, lesions deemed malignant would proceed to definitive surgical treatment via either lobectomy or total thyroidectomy (1). To this end, molecular tests can be broadly thought of as "rule out" or "rule in" tests for malignancy. The Afirma-GEC is primarily a "rule out" test designed to identify benign biology and thus spare surgery, while the ThyroSeq assay is a "rule in" test that aims to identify nodules that harbor malignancy and thus best treated with surgery (18). However, herein, we aim to carefully examine the real utility of using these molecular panels in the algorithmic approach to thyroid nodule clinical management.

\section{Afirma}

In their seminal paper describing the performance of AfirmaGEC, Alexander and colleagues reported this test to have negative predictive values (NPV) of 95 and $94 \%$ for cytologically indeterminate nodules in the AUS-FLUS and FNSFN categories, respectively (19). These initial excellent numbers suggested that the GEC test could "rule out" malignancy (and thus spare diagnostic surgery) in over $90 \%$ of indeterminate nodules, thereby making an substantial case for its implementation into clinical practice. However, subsequent reports have questioned the reproducibility of these results. In particular, later studies have reported that the NPV of AfirmaGEC varied greatly depending on the institution where the FNA biopsies were performed, and in one case was noted to be as low as $69 \%(7,20-23)$. This inter-institutional variation is believed to stem from differences in malignancy prevalence within the evaluated populations. For instance, Marti and colleagues discovered that within the same city, the pre-test malignancy probability of an indeterminate thyroid nodule ranged from 30 to $38 \%$ at a cancer center vs. $10-19 \%$ for a general hospital, and correspondingly, the NPV for GEC was lower at the cancer center (86-92\% vs. 95-98\%) (22). Conversely, the positive predictive value (PPV) at the general hospital was too low ( 14.3 vs. $57.1 \%$ at the cancer center), and $86 \%$ of the nodules that were resected at that institution based on GEC-suspicious result were ultimately benign on final pathology (22). Furthermore, Al-Qurayshi and colleagues in their extensive analysis of GEC test performance found that this variability could not be accounted for solely by differences in malignancy prevalence, suggesting intrinsic variations in the test's performance (sensitivity and specificity) (21). The authors highlight that most publications reporting on test performance were at high risk of selection bias given that they were based at single institutions and had relatively small sample sizes (average, 108 nodules). Both impede defining a true sensitivity and specificity value for the test (21). Finally, it has been shown that the GEC does not perform equally across all thyroid nodule histopathology. In particular, studies have demonstrated that samples containing a predominance of Hürthle cells may falsely categorized as being "suspicious" and lead to excessive surgeries in patients with this cytopathology $(24,25)$. Due to these myriad challenges to its accuracy and NPV, the utilization and 
interpretation of Afirma test results, in each individual clinical setting, must be thoughtfully considered as it is well known that risk of malignancies, cytology, and pathology results differ across institutions.

\section{ThyroSeq}

Much like the GEC, inter institutional variability has also been observed with ThyroSeq V2. In its initial validation study, this test was reported to have a positive predictive value of $83 \%$; however, this number was found to be drastically lower at 22$43 \%$ in a survey of this test's performance across various institutions by Marcadis and colleagues $(26,27)$. A similarly low positive predictive value was also reported by Taye and colleague, which casts doubts on this "rule in" test's ability to accurately identify malignant nodules that require surgical intervention (28). Moreover, both these studies as well as a previous report by Valderrabano and colleagues reported the RAS family of oncogenes to be the most commonly mutated genes in their samples (29). Indeed, although RAS mutations have been demonstrated to be oncogenic drivers in a number of cancer types (such as colon, lung, and pancreas), their role in thyroid malignancy is less well defined. Indeed, in both the Marcadis et al. and Taye et al. studies, the positive predictive value of RAS mutations was found to be between only 7 and $25 \%$, a number that has been replicated by a more recent and in-depth analysis by Guan and colleagues $(26,28,30)$. In a systematic review by Najafian et al. RAS mutations have also been shown to be frequently present in benign thyroid nodules, thus further weakening their utility as a oncogenic marker in thyroid cancer (31). Taken together, these results suggest that i) the positive predictive value of ThyroSeq V2 is lower than initially reported and ii) the most common genetic alteration used to establish malignancy by this test may in fact not be a bona fide marker of malignant behavior in thyroid cancer.

\section{Noninvasive Follicular Thyroid Neoplasm With Papillary-Like Nuclear Features and Its Implication}

Compounding the challenge to the accuracy of molecular testing is the recent introduction of a new thyroid pathological entity: noninvasive follicular thyroid neoplasm with papillary-like nuclear features (NIFTP). The NIFTP category was created to distinguish an indolent class of encapsulated follicular variant of papillary thyroid carcinoma from other aggressive forms of papillary thyroid cancer. Of note, its average prevalence within indeterminate thyroid nodules is estimated to be $61 \%$ (range, 33$81 \%)(32,33)$. Given that these mainstay molecular tests were developed and validated prior to this re-designation (and thus designed to classify this potential benign pathology as malignant), their performance measures have been shown to deteriorate significantly when the NIFTP designation is incorporated in the classification of indeterminate nodules (20, 28, 33-35). For instance, the NPV of Affirma GEC declined from 96 to $81 \%$ when the NIFTP designation was retrospectively applied to the cohort studied by Samulski and colleagues (35). Similarly, in the cohort studied by Valderrabano and colleagues, the PPV of ThyroSeq V2 decreased from 42 to $33 \%$ when NIFTP lesions were considered benign (29). The performance of the ThyroSeq "rule in" test appears to be more significantly affected by NIFTP reclassification than the Afirma "rule out" test. Nevertheless, the results of both should be interpreted with a consideration that benign NIFTP lesions may be falsely classified as suspicious, and thus subjected to unnecessary surgery by these tests.

\section{Newer Editions-Afirma-GSC and ThyroSeq V3}

Ultimately, the newer versions of these commercial tests appear to be addressing and improving upon these diagnostic limitations. The ThyroSeq V3 test, for instance, has been demonstrated to have a NPV of $97 \%$, and benign call rates of $61 \%$ for indeterminate nodules and $53 \%$ for nodules with Hürthle cells (9). For the Afirma-GSC, San Martin and colleagues found that the second generation test has a higher specificity (94 vs. $60 \%$ ) while retaining similar negative predictive value (96.3 vs. $98.6 \%$ ) compared to the GEC. This resulted in improved performance within specimens with Hürthle cell cytology, improved overall benign call rate of $68 \%$ ( $v s .41 \%)$ and a decrease in surgery rate from 48 to $35 \%$ for the population as a whole (36). Wei and colleagues have documented that the benign call rate for GSC is considerably higher than GEC (66.7 vs. $45.4 \%$ ), and Endo and colleagues have reported a benign call rate of 88.8 vs. $25.7 \%$ for GSC vs. GEC for samples with Hürthle cells $(37,38)$. Both these papers, as well as comparative study by Harrell and colleagues, suggested that the rate of surgical intervention was lower during the period when the newer test was utilized (39). However, discrepancies between these initial reports and experience from real world usage are already appearing; Chen and colleagues, for instance, found that the benign call rate of GEC was only $58 \%$ compared to the $74 \%$ reported in an earlier publication $(40,41)$. Ultimately, as was learned in the case of Afirma-GEC and ThyroSeq V2, these initial findings and test performances need to be confirmed in both independent validation studies and in larger cohorts. Until then, caution should be urged regarding the application and interpretation of these tests in achieving both diagnostic certainty and truly impacting clinical care in patients with indeterminate thyroid nodules.

\section{IMPACT ON SURGICAL PRACTICE}

One of the stated aims of molecular testing for indeterminate thyroid nodules is to assess the risk for malignancy, and thus determine 1) whether surgery is appropriate for that lesion and 2 ), if so, the extent of surgery. A corollary aim to this is reducing the number of diagnostic lobectomies performed, and ultimately spare a patient from the risks and costs of unnecessary surgery. While most studies examining the utility of these molecular tests center on their diagnostic performance (i.e., sensitivity, specificity, NPV, and PPV), investigations on whether implementation of these tests lead to actual changes in surgical 
utilization and clinical practice patterns are sparse. Prospective studies assessing the impact of these tests on the rate and appropriateness of surgical intervention are lacking, and most of the information is gleaned from retrospective data only. Moreover, many of the series suggesting that implementation of molecular testing leads to reduction in number of surgeries are correlative in nature, i.e., they show that fewer surgeries were done during period of molecular testing use compared to historical time period when testing was not used, but they do not directly show a causal effect at the individual patient/nodule level $(36,39,42)$.

\section{Impact on Surgical Decision Making}

One of the first studies to specifically investigate molecular testing's impact on surgical management was a retrospective study performed by Aragon Han and colleagues in 2014 (43) (Table 1). Here, the authors compared management recommendations based on pre-operative molecular testing results to the treatment strategy recommended by a surgical management algorithm. The algorithm was based on clinical parameters developed by experts at a high-volume, tertiary academic institution and in incorporated into a calculator. They found that the strategy influenced by molecular testing differed from the recommendations of the clinical management algorithm in only $10 \%$ of the patients (9/87). Furthermore, in 6 out these $9(67 \%)$ patients the molecular testing driven strategy was incorrect and led to overtreatment. Similar results were subsequently observed during two successive investigations by Noureldine and colleagues $(44,45)$. In one, the authors specifically looked at the appropriateness and impact of Afirma-GEC on management of 273 patients using a similar strategy to Aragon Han et al. and found that the GEC results changed management strategy in just 23 out of 273 patients
(8.4\%) and led to overtreatment in most of these (72.7\%) (44). These results were echoed by a subsequent prospective study by the same group where molecular testing only changed management plan in $7.9 \%$ patients, out of whom $91 \%$ were overtreated (45) (Table 1).

Strikingly, Noureldine and colleagues found that over $50 \%$ of the patients who underwent molecular testing did not meet clinical guideline criteria for molecular testing (i.e., already had indications for surgical intervention based on clinical assessment), suggesting that these tests were being inappropriately ordered for a large number of patients whose treatment could be dictated by clinical findings alone. Specifically, clinical parameters alone clearly informed what surgical procedure should be performed. Inappropriate implementation and interpretation of molecular testing was also highlighted by Samulski et al. in their description of GEC utilization at their institution, where they noted that most lesions not designated as "Benign" by GEC ultimately underwent surgical resection, even when the sample was classified as "QNS" (quantity not sufficient) and despite the fact that the GEC is a "rule out" test (35). Indeed, 7 out of 13 of these "QNS" lesions in this study were ultimately shown to be benign on final pathology. Taken together, these four studies suggest that 1) molecular testing results influence management strategies in a limited number of patients ( $<10 \%$ of cases), 2$)$ when the strategy does get altered based on molecular testing, there exists a real and significant risk of overdiagnosis and overtreatment, and 3) these tests are often being misused indiscriminately in cases where management decisions can and should be made based on clinical features alone.

Can molecular testing results be used to tailor the extent of surgery for indeterminate nodules? An early investigation by Yip and colleagues appeared to suggest that molecular testing results could guide the decision to offer total thyroidectomy (vs. a

TABLE 1 | Summary of investigations evaluating impact of molecular testing on surgical management and outcomes.

\begin{tabular}{|c|c|c|c|c|c|c|}
\hline Series & $\begin{array}{c}\text { Study } \\
\text { duration }\end{array}$ & $\begin{array}{c}\text { Publication } \\
\text { year }\end{array}$ & Test & Design & $\begin{array}{c}\text { Number of } \\
\text { patients }\end{array}$ & Impact of molecular testing \\
\hline $\begin{array}{l}\text { Aragon Han, P. } \\
\text { et al. (43) }\end{array}$ & $\begin{array}{l}2009 \\
2013\end{array}$ & 2014 & GEC, Mutation Panel & Retrospective & 87 & $\begin{array}{l}78 / 87(90 \%) \text { no change in management } \\
9 / 87(10 \%) \text { surgical plan altered } \\
6 / 9(67 \%) \text { change inappropriate } \\
5 / 6(83 \%) \text { inappropriately overtreated }\end{array}$ \\
\hline $\begin{array}{l}\text { Noureldine, S. } \\
\text { et al. (44) }\end{array}$ & $\begin{array}{l}2012- \\
2014\end{array}$ & 2015 & GEC & Retrospective & 273 & $\begin{array}{l}250 / 273(92 \%) \text { no change in management } \\
23 / 273(8 \%) \text { surgical plan altered } \\
16 / 23(73 \%) \text { inappropriately overtreated }\end{array}$ \\
\hline $\begin{array}{l}\text { Marti, J. et al. } \\
\text { (22) }\end{array}$ & $\begin{array}{l}2013- \\
2014\end{array}$ & 2015 & GEC & Retrospective & 165 & $\begin{array}{l}\text { At cancer center: } \\
\text { 42/70 (60\%) GEC suspicious lesions resected } \\
\text { 18/42 (43\%) GEC suspicious resected lesions ultimately benign } \\
\text { (inappropriately overtreated) } \\
\text { At general hospital: } \\
21 / 34(62 \%) \text { GEC suspicious lesions resected } \\
\text { 18/21 (86\%) GEC suspicious resected lesions ultimately benign } \\
\text { (inappropriately overtreated) }\end{array}$ \\
\hline $\begin{array}{l}\text { Noureldine, S. } \\
\text { et al. (45) }\end{array}$ & $\begin{array}{l}2014- \\
2015\end{array}$ & 2016 & $\begin{array}{l}\text { GEC, ThyroSeq, } \\
\text { Mutation Panel }\end{array}$ & Prospective & 140 & $\begin{array}{l}129 / 140(92 \%) \text { no change in management } \\
11 / 140(8 \%) \text { surgical plan altered } \\
10 / 11(91 \%) \text { inappropriately overtreated }\end{array}$ \\
\hline $\begin{array}{l}\text { Taye, A. et al. } \\
\text { (28) }\end{array}$ & $\begin{array}{l}2014- \\
2016\end{array}$ & 2018 & ThyroSeq & Retrospective & 156 & $\begin{array}{l}37 / 51 \text { (73\%) ThyroSeq suspicious lesions resected } \\
29 / 37 \text { (78\%) ThyroSeq suspicious resected lesions ultimately } \\
\text { benign (inappropriately overtreated) }\end{array}$ \\
\hline
\end{tabular}


diagnostic lobectomy) in lesions with high risk features identified by molecular testing (46). In this study, a positive result in a six gene (BRAF, NRAS, HRAS, KRAS, RET-PTC, and PAX8PPARy) molecular test panel was used as an indicator for total thyroidectomy for cytologically indeterminate nodule. This approach increased the appropriate use (based on final pathology) of total thyroidectomy by $30 \%$ and reduced the rate of lobectomy by $33 \%$, thereby suggesting that molecular testing results could identify malignancy and thus appropriately direct care toward total thyroidectomy while sparing a second operation for completion thyroidectomy in a number of patients. However, a major limitation of this study was incomplete reporting on the rate of false positive outcomes for the molecular test panel (i.e., the number of lesions where unnecessary total thyroidectomy was performed for positive molecular testing result that was ultimately benign on final pathology was not reported). Furthermore, the study was not blinded for the post-operative histopathological assessment of the specimen and, as such, the molecular testing results could have influenced whether an indeterminate lesion was determined as malignant on final pathology, thereby confounding the correlation between pre-operative molecular testing and postoperative pathological assessment. Subsequent investigations into the use of molecular testing, and in particular the commercial tests, in guiding extent of surgery have been limited to case reports [c.f. (47)].

\section{Implications of New Surgical Guidelines for Thyroid Cancer and NIFTP Diagnosis}

Additionally, the utility of molecular testing in guiding the extent of surgery is undermined by changes in clinical guidelines regarding the extent of surgery. The American Thyroid Association, for instance, has suggested that differentiated thyroid cancer $<4 \mathrm{~cm}$ may be safely treated with lobectomy instead of traditionally performed total thyroidectomy, since limited resection has equivalent outcomes to extensive surgery in select patients $(1,48)$. Given that fact that more limited cancer operation can lead to equivalent outcomes while sparing patients from important side effects (e.g., need for thyroid hormone replacement after total thyroidectomy), the impact of molecular testing in directing the extent of surgical resection becomes even more diminished.

The advent of NIFTP as a new entity in thyroid nodule classification is another confounding factor undermining the utility of molecular markers in deciding to perform surgery. As discussed above, introduction of the NIFTP terminology to define a more indolent form of thyroid neoplasm significantly affects the diagnostic performance of these molecular tests (33). Additionally, while NIFTP remains a surgically treated entity, the lack of invasive features suggest that a thyroid lobectomy, as opposed to total thyroidectomy, may suffice in its management (49). Given that the commercial molecular tests tend to classify NIFTP lesions as "suspicious," reliance on these results may lead to overtreatment in the form of total thyroidectomy in lesions that could otherwise be managed by lobectomies. In the face of evolving guidelines and understanding of thyroid cancer biology that now suggests a role for more limited surgical resection, the guidance provided by these molecular markers becomes limited in its scope. Ultimately, it is recommended that the extent of surgery should be determined primarily by clinical variables, ultrasound findings, and individual patient preference $(50,51)$.

Why does molecular testing, despite the much touted improvement in diagnostic accuracy, fail to have a significant effect on the ultimate decision regarding surgical approach? In addition to the real risk of overdiagnosis and overtreatment summarized above, one hypothesis is that the overall impact of molecular testing on management decision, when compared to that of clinical and radiographic features, is incremental at best. For instance, a recent investigation by Huang and colleagues have suggested that while supplementing clinical information with imaging and cytopathology improved diagnostic accuracy significantly, further incorporation of molecular testing results to these variables led to only a modest and negligible improvement to overall diagnostic capacity (17). Similarly, Vora and colleagues found in their single institution experience that patients with clinical indications for surgery (such as compressive symptoms, interval growth of nodules, and presence of secondary nodules) underwent surgical intervention at high rates despite "benign" calls in the GEC, with $30 \%$ of these lesions ultimately being found to harbor malignancy (52). As such, decision-making regarding surgery (be it whether to operate or how much to resect) remains best determined by clinical factors and the true impact of molecular testing results appear to be limited at best.

\section{COST-EFFECTIVENESS ANALYSIS}

Thyroid surgery, like any invasive procedure, is associated with both direct (e.g., operating room equipment, professional fees, etc.) and indirect costs (e.g., time out of work for the patient, postoperative complications, etc.). It has been postulated that molecular testing can help reduce these costs by more definitively identifying benign nodules and thereby sparing unnecessary surgeries. This claim is put forth in part because despite their own high costs $(\$ 4,875$ for Afirma-GEC, $\$ 6,400$ for Afirma-GSC, and $\$ 3,200$ for Thyroseq V2/3), these molecular tests are cheaper than the $\$ 9,000-12,000$ cost estimate for a diagnostic lobectomy $(13,53)$. Additionally, there are a number of studies based on complex modeling of hypothetical clinical scenarios and cost estimates that claim that molecular markers are more cost effective than diagnostic lobectomy $(18,53,54)$.

However, similar modeling studies have also suggested that these tests are not cost effective, particularly at their current price points. Najafzadeh and colleagues, for instance, have estimated that the "break even" price at which molecular tests become costeffective is approximately $\$ 1,087$, which is significantly lower than the $\$ 3,000-6,000$ currently being charged for these tests (55). Moreover, a significant limitation of such cost-analysis simulations is that the parameters upon which the models are based (such as assumptions regarding direct costs, diagnostic accuracy, cancer prevalence in the target population, and outcomes after molecular testing vs. thyroid surgery) are 
typically estimations and averages that in reality can vary greatly amongst institutions. These variables make the findings of these modeling difficult to generalize to real-world situations. Many of the simulations, for instance, have been shown to be sensitive to the direct cost estimates used for modeling (i.e., changing the direct cost variable influences whether molecular testing comes out as cost-effective or not), with some suggesting that the price of these molecular tests need to be lowered in order to achieve cost-effectiveness $(18,56)$. Finally, in an elegant study incorporating sonographic factors into cost-effectiveness modeling, Zanocco and colleagues noted that molecular testing failed to be cost-effective when lesions already harbored suspicious imaging features (56). This, again, reflected the concept that while attractive in isolation, molecular testing had limited incremental benefit when interpreted in the context of other clinical features in the multidisciplinary evaluation of thyroid nodules. Reports on actual cost accounting after implementation of molecular testing have also suggested limited cost-effectiveness of this technology. A retrospective study reviewing the actual costs incurred after the implementation of molecular testing, for instance, have reported increased costs per patient (57). Applying modeling to real world data obtained retrospectively, Shapiro and colleagues demonstrated that while Afirma utilization could lead to a reduction in the absolute number of patients undergoing surgery (by 13\%), its use led to increased overall cost per nodule ( $\$ 2,399$ higher compared to no molecular testing over 2 years) given that once classified as "suspicious" on molecular testing these nodules entailed further follow-up interventions (such as repeat biopsy down the road or surveillance imaging) (58). An increase in cost associated with need for ongoing surveillance was also independently demonstrated by Balentine and colleagues who estimated that the lobectomy cost of $\$ 6,100$ per nodule was significantly less than that for molecular testing (Afirma, \$9,400) when calculated over a 5-year period (59). Indeed, Lin and colleagues have estimated that while surgery upfront is more expensive than annual surveillance, this cost difference is reversed by just 16 years of surveillance, which is considerably less than the expected lifespan of these patients (60). Thus, in the long term, surgery may in fact be more cost effective than surveillance for high risk nodules.

\section{CONCLUSIONS AND FUTURE DIRECTIONS}

The field of molecular testing for thyroid nodules is expanding rapidly, and incorporation of these tests into the management algorithm for indeterminate thyroid nodules is now advocated by major societal guidelines. While considerable literature exists on the diagnostic performance of commercial molecular tests, there are some major limitations to their application, interpretation, clinical impact, and cost which should be addressed before their routine use (summarized in Table 2). Specifically, the variability in diagnostic accuracy posed by variations in test performance and the NIFTP designation, the lack of any true study documenting an impact and appropriate change on surgical management, and the "real world" studies undermining the cost-effectiveness touted by previous modeling studies, all raise concerns regarding the widespread utilization and reliance on these molecular markers. Like any diagnostic test, these expensive investigations are best used in a thoughtful manner and in a case-by-case basis for nodules with equivocal clinical, cytopathologic, and radiographic factors as recommended by professional societies such as the American Thyroid Association and American Association for Endocrine Surgeons. Molecular testing should only be considered if the result of a test would otherwise alter the recommended management of the patient. Indiscriminate and routine use for any suspicious thyroid nodule should certainly be avoided as it could lead to overdiagnosis, increased costs, and most importantly may have no impact on surgical management. Moreover, consideration should also be given to the diagnostic improvement provided by alternate modalities, such as imaging. The American College of Radiology, for instance, has developed the Thyroid Imaging, Reporting, and Data System (TIRADS) algorithm that ascribes malignancy risk to thyroid nodules based on its composition, echogenicity, shape, size, and margins and can provide useful additive information to Bethesda cytology results over that provided by molecular markers (4).

Ultimately, given our increasing understanding of thyroid cancer biology, molecular testing needs to become more precise and directed specifically toward informing what therapy to offer once thyroid cancer is diagnosed, [such as by the identification of actionable RET, NRTK, BRAF, VEGFR mutations, and pathway

TABLE 2 | Advantages and limitations of existing commercial molecular markers.

Category Consideration

Diagnostic utility

Advantage: Afirma testing for Bethesda III-IV, if negative and no other indications for surgery, may obviate surgery Disadvantage: Variability in test performance depending on cancer prevalence rates

Disadvantage: Variability of results depending on underlying cytopathology and histopathology

Disadvantage: Lack of definite correlation between measured biomarker (e.g., RAS mutation) and malignancy

Disadvantage: Introduction of NIFTP diagnosis decreasing risk of malignancy and studies upon which diagnostic marker results determined

Impact on surgical decision Advantage: BRAF and HTERT results may inform adjunctive therapy recommendations

making Disadvantage: Limited influence on treatment algorithms otherwise based on clinical and radiographic factors Disadvantage: Impact on extent of surgery (e.g., lobectomy vs. total thyroidectomy) minimized by changes in surgical guidelines supporting lobectomy for tumors up to $4 \mathrm{~cm}$.

Cost effectiveness Disadvantage: Extremely high costs for molecular testing exceeding estimated "breakeven" cost of $\sim \$ 1,000$ 
alterations that would allow for the use of targeted agents (6164)]. For instance, there are exciting advanced being made in the research setting on development of new molecular markers (e.g., TERT expression) that can improve prognostication and treatment of thyroid cancer (65). These areas of study are more promising for the treatment of advanced thyroid cancer than what appears to be only incremental changes provided in the diagnosis of indeterminate thyroid nodules. Ultimately, molecular tests should clarify the management algorithm and

\section{REFERENCES}

1. Haugen BR, Alexander EK, Bible KC, Doherty GM, Mandel SJ, Nikiforov YE, et al. American Thyroid Association Management Guidelines for Adult Patients with Thyroid Nodules and Differentiated Thyroid Cancer: The American Thyroid Association Guidelines Task Force on Thyroid Nodules and Differentiated Thyroid Cancer. Thyroid (2015) 26:(2016) 1-133. doi: $10.1089 /$ thy. 2015.0020

2. Gharib H, Papini E, Garber JR, Duick DS, Harrell RM, Hegedus L, et al. Nodules, American Association of Clinical Endocrinologists, American College of Endocrinology, and Associazione Medici Endocrinologi Medical Guidelines for Clinical Practice for the Diagnosis and Management of Thyroid Nodules-2016 Update. Endocr Pract (2016) 22:622-39. doi: 10.4158/EP161208.GL

3. Patel KN, Yip L, Lubitz CC, Grubbs EG, Miller BS, Shen W, et al. The American Association of Endocrine Surgeons Guidelines for the Definitive Surgical Management of Thyroid Disease in Adults. Ann Surg (2020) 271: e21-93. doi: 10.1097/SLA.0000000000003580

4. Grant EG, Tessler FN, Hoang JK, Langer JE, Beland MD, Berland LL, et al. Thyroid Ultrasound Reporting Lexicon: White Paper of the ACR Thyroid Imaging, Reporting and Data System (TIRADS) Committee. J Am Coll Radiol (2015) 12:1272-9. doi: 10.1016/j.jacr.2015.07.011

5. Tessler FN, Middleton WD, Grant EG, Hoang JK, Berland LL, Teefey SA, et al. Thyroid Imaging, Reporting and Data System (TI-RADS): White Paper of the ACR TI-RADS Committee. J Am Coll Radiol (2017) 14:587-95. doi: 10.1016/j.jacr.2017.01.046

6. Cibas ES, Ali SZ. The 2017 Bethesda System for Reporting Thyroid Cytopathology. Thyroid (2017) 27:1341-6. doi: 10.1089/thy.2017.0500

7. Sahli ZT, Smith PW, Umbricht CB, Zeiger MA. Preoperative Molecular Markers in Thyroid Nodules. Front Endocrinol (Lausanne) (2018) 9:179. doi: 10.3389/fendo.2018.00179

8. Mayson SE, Haugen BR. Molecular Diagnostic Evaluation of Thyroid Nodules. Endocrinol Metab Clin North Am (2019) 48:85-97. doi: 10.1016/ j.ecl.2018.10.004

9. Steward DL, Carty SE, Sippel RS, Yang SP, Sosa JA, Sipos JA, et al. Performance of a Multigene Genomic Classifier in Thyroid Nodules With Indeterminate Cytology: A Prospective Blinded Multicenter Study. JAMA Oncol (2019) 5:204-12. doi: 10.1001/jamaoncol.2018.4616

10. Patel KN, Angell TE, Babiarz J, Barth NM, Blevins T, Duh QY, et al. Performance of a Genomic Sequencing Classifier for the Preoperative Diagnosis of Cytologically Indeterminate Thyroid Nodules. JAMA Surg (2018) 153:817-24. doi: 10.1001/jamasurg.2018.1153

11. Yip L, Sosa JA. Molecular-Directed Treatment of Differentiated Thyroid Cancer: Advances in Diagnosis and Treatment. JAMA Surg (2016) 151:66370. doi: 10.1001/jamasurg.2016.0825

12. Eszlinger M, Bohme K, Ullmann M, Gorke F, Siebolts U, Neumann A, et al. Evaluation of a Two-Year Routine Application of Molecular Testing of Thyroid Fine-Needle Aspirations Using a Seven-Gene Panel in a Primary Referral Setting in Germany. Thyroid (2017) 27:402-11. doi: 10.1089/ thy.2016.0445

13. Kuo JH, McManus C, Graves CE, Madani A, Khokhar MT, Huang B, et al. Updates in the management of thyroid nodules. Curr Prob Surg (2019) 56:103-27. doi: 10.1067/j.cpsurg.2018.12.003 thus enable us to take more optimal care of patients with thyroid nodules, instead of introducing another layer of information that may be unnecessary and costly.

\section{AUTHOR CONTRIBUTIONS}

TK and MZ designed, wrote, and edited the manuscript. All authors contributed to the article and approved the submitted version.
14. Patel KN, Yip L, Lubitz CC, Grubbs EG, Miller BS, Shen W, et al. Executive Summary of the American Association of Endocrine Surgeons Guidelines for the Definitive Surgical Management of Thyroid Disease in Adults. Ann Surg (2020) 271:399-410. doi: 10.1097/SLA.0000000000003580

15. Haddad RI, Nasr C, Bischoff L, Busaidy NL, Byrd D, Callender G, et al. NCCN Guidelines Insights: Thyroid Carcinoma, Version 2.2018. J Natl Compr Canc Netw (2018) 16:1429-40. doi: 10.6004/jnccn.2018.0089

16. Ferris RL, Baloch Z, Bernet V, Chen A, Fahey, 3rd TJ, Ganly I, et al. American Thyroid Association Statement on Surgical Application of Molecular Profiling for Thyroid Nodules: Current Impact on Perioperative Decision Making. Thyroid (2015) 25:760-8. doi: 10.1089/thy.2014.0502

17. Huang BL, Chabot JA, Lee JA, Kuo JH. A stepwise analysis of the diagnostic algorithm for the prediction of malignancy in thyroid nodules. Surgery (2020) 167:28-33. doi: 10.1016/j.surg.2019.05.079

18. Eszlinger M, Lau L, Ghaznavi S, Symonds C, Chandarana SP, Khalil M, et al. Molecular profiling of thyroid nodule fine-needle aspiration cytology. Nat Rev Endocrinol (2017) 13:415-24. doi: 10.1038/nrendo.2017.24

19. Alexander EK, Kennedy GC, Baloch ZW, Cibas ES, Chudova D, Diggans J, et al. Preoperative diagnosis of benign thyroid nodules with indeterminate cytology. N Engl J Med (2012) 367:705-15. doi: 10.1056/NEJMoa1203208

20. Valderrabano P, Hallanger-Johnson JE, Thapa R, Wang X, McIver B. Comparison of Postmarketing Findings vs the Initial Clinical Validation Findings of a Thyroid Nodule Gene Expression Classifier: A Systematic Review and Meta-analysis. JAMA Otolaryngol Head Neck Surg (2019) 145:783-92. doi: 10.1001/jamaoto.2019.1449

21. Al-Qurayshi Z, Deniwar A, Thethi T, Mallik T, Srivastav S, Murad F, et al. Association of Malignancy Prevalence With Test Properties and Performance of the Gene Expression Classifier in Indeterminate Thyroid Nodules. JAMA Otolaryngol Head Neck Surg (2017) 143:403-8. doi: 10.1001/jamaoto. 2016.3526

22. Marti JL, Avadhani V, Donatelli LA, Niyogi S, Wang B, Wong RJ, et al. Wide Inter-institutional Variation in Performance of a Molecular Classifier for Indeterminate Thyroid Nodules. Ann Surg Oncol (2015) 22:3996-4001. doi: 10.1245/s10434-015-4486-3

23. Kay-Rivest E, Tibbo J, Bouhabel S, Tamilia M, Leboeuf R, Forest VI, et al. The first Canadian experience with the Afirma(R) gene expression classifier test J Otolaryngol Head Neck Surg (2017) 46:25. doi: 10.1186/s40463-017-0201-7

24. Parajuli S, Jug R, Ahmadi S, Jiang XS. Hurthle cell predominance impacts results of Afirma gene expression classifier and ThyroSeq molecular panel performance in indeterminate thyroid nodules. Diagn Cytopathol (2019) 47:1177-83. doi: $10.1002 /$ dc. 24290

25. Brauner E, Holmes BJ, Krane JF, Nishino M, Zurakowski D, Hennessey JV, et al. Performance of the Afirma Gene Expression Classifier in Hurthle Cell Thyroid Nodules Differs from Other Indeterminate Thyroid Nodules. Thyroid (2015) 25:789-96. doi: 10.1089/thy.2015.0049

26. Marcadis AR, Valderrabano P, Ho AS, Tepe J, Swartzwelder CE, Byrd S, et al. Interinstitutional variation in predictive value of the ThyroSeq v2 genomic classifier for cytologically indeterminate thyroid nodules. Surgery (2019) 165:17-24. doi: 10.1016/j.surg.2018.04.062

27. Nikiforov YE, Carty SE, Chiosea SI, Coyne C, Duvvuri U, Ferris RL, et al. Highly accurate diagnosis of cancer in thyroid nodules with follicular neoplasm/ suspicious for a follicular neoplasm cytology by ThyroSeq v2 next-generation sequencing assay. Cancer (2014) 120:3627-34. doi: 10.1002/cncr.29038 
28. Taye A, Gurciullo D, Miles BA, Gupta A, Owen RP, Inabnet 3WB, et al. Clinical performance of a next-generation sequencing assay (ThyroSeq v2) in the evaluation of indeterminate thyroid nodules. Surgery (2018) 163:97-103. doi: 10.1016/j.surg.2017.07.032

29. Valderrabano P, Khazai L, Leon ME, Thompson ZJ, Ma Z, Chung CH, et al. Evaluation of ThyroSeq v2 performance in thyroid nodules with indeterminate cytology. Endocr Relat Cancer (2017) 24:127-36. doi: 10.1530/ERC-16-0512

30. Guan H, Toraldo G, Cerda S, Godley FA, Rao SR, McAneny D, et al. Utilities of RAS Mutations in Preoperative Fine Needle Biopsies for Decision Making for Thyroid Nodule Management: Results from a Single-Center Prospective Cohort. Thyroid (2020) 30:536-47. doi: 10.1089/thy.2019.0116

31. Najafian A, Noureldine S, Azar F, Atallah C, Trinh G, Schneider EB, et al. RAS Mutations, and RET/PTC and PAX8/PPAR-gamma Chromosomal Rearrangements Are Also Prevalent in Benign Thyroid Lesions: Implications Thereof and A Systematic Review. Thyroid (2017) 27:39-48. doi: $10.1089 /$ thy.2016.0348

32. Nikiforov YE, Seethala RR, Tallini G, Baloch ZW, Basolo F, Thompson LD, et al. Nomenclature Revision for Encapsulated Follicular Variant of Papillary Thyroid Carcinoma: A Paradigm Shift to Reduce Overtreatment of Indolent Tumors. JAMA Oncol (2016) 2:1023-9. doi: 10.1001/jamaoncol.2016.0386

33. Sahli ZT, Umbricht CB, Schneider EB, Zeiger MA. Thyroid Nodule Diagnostic Markers in the Face of the New NIFTP Category: Time for a Reset? Thyroid (2017) 27:1393-9. doi: 10.1089/thy.2017.0238

34. Hang JF, Westra WH, Cooper DS, Ali SZ. The impact of noninvasive follicular thyroid neoplasm with papillary-like nuclear features on the performance of the Afirma gene expression classifier. Cancer Cytopathol (2017) 125:683-91. doi: $10.1002 /$ cncy. 21879

35. Samulski TD, LiVolsi VA, Wong LQ, Baloch Z. Usage trends and performance characteristics of a "gene expression classifier" in the management of thyroid nodules: An institutional experience. Diagn Cytopathol (2016) 44:867-73. doi: 10.1002/dc.23559

36. San Martin VT, Lawrence L, Bena J, Madhun NZ, Berber E, Elsheikh TM, et al. Real-world Comparison of Afirma GEC and GSC for the Assessment of Cytologically Indeterminate Thyroid Nodules. J Clin Endocrinol Metab (2020) 105(3):e428-35. doi: 10.1210/clinem/dgz099

37. Wei S, Veloski C, Sharda P, Ehya H. Performance of the Afirma genomic sequencing classifier versus gene expression classifier: An institutional experience. Cancer Cytopathol (2019) 127:720-4. doi: 10.1002/cncy.22188

38. Endo M, Nabhan F, Porter K, Roll K, Shirley LA, Azaryan I, et al. Afirma Gene Sequencing Classifier Compared with Gene Expression Classifier in Indeterminate Thyroid Nodules. Thyroid (2019) 29:1115-24. doi: 10.1089/ thy.2018.0733

39. Harrell RM, Eyerly-Webb SA, Golding AC, Edwards CM, Bimston DN. Statistical Comparison of Afirma Gsc and Afirma Gec Outcomes in a Community Endocrine Surgical Practice: Early Findings. Endocr Pract (2019) 25:161-4. doi: 10.4158/EP-2018-0395

40. Chen T, Gilfix B, Rivera JA, Sadeghi N, Richardson K, Hier MP, et al. The Role of the ThyroSeq v3 Molecular Test in the Surgical Management of Thyroid Nodules in the Canadian Public Healthcare Setting. Thyroid (2020) 30:12807. doi: 10.1089/thy.2019.0539

41. Ohori NP, Landau MS, Carty SE, Yip L, LeBeau SO, Manroa P, et al. Benign call rate and molecular test result distribution of ThyroSeq v3. Cancer Cytopathol (2019) 127:161-8. doi: 10.1002/cncy.22088

42. Jug R, Parajuli S, Ahmadi S, Jiang XS. Negative Results on Thyroid Molecular Testing Decrease Rates of Surgery for Indeterminate Thyroid Nodules. Endocr Pathol (2019) 30:134-7. doi: 10.1007/s12022-019-9571-x

43. Aragon Han P, Olson MT, Fazeli R, Prescott JD, Pai SI, Schneider EB, et al. The impact of molecular testing on the surgical management of patients with thyroid nodules. Ann Surg Oncol (2014) 21:1862-9. doi: 10.1245/s10434-0143508-x

44. Noureldine SI, Olson MT, Agrawal N, Prescott JD, Zeiger MA, Tufano RP. Effect of Gene Expression Classifier Molecular Testing on the Surgical Decision-Making Process for Patients With Thyroid Nodules. JAMA Otolaryngology-Head Neck Surg (2015) 141(12):1082-8. doi: 10.1001/ jamaoto.2015.2708

45. Noureldine SI, Najafian A, Aragon Han P, Olson MT, Genther DJ, Schneider EB, et al. Evaluation of the Effect of Diagnostic Molecular Testing on the Surgical Decision-Making Process for Patients With Thyroid Nodules. JAMA
Otolaryngol Head Neck Surg (2016) 142:676-82. doi: 10.1001/jamaoto. 2016.0850

46. Yip L, Wharry LI, Armstrong MJ, Silbermann A, McCoy KL, Stang MT, et al. A clinical algorithm for fine-needle aspiration molecular testing effectively guides the appropriate extent of initial thyroidectomy. Ann Surg (2014) 260:163-8. doi: 10.1097/SLA.0000000000000215

47. Pearlstein S, Lahouti AH, Opher E, Nikiforov YE, Kuriloff DB. Thyroseq V3 Molecular Profiling for Tailoring the Surgical Management of Hurthle Cell Neoplasms. Case Rep Endocrinol (2018) 2018:9329035. doi: 10.1155/2018/ 9329035

48. Tufano RP, Shindo M, Shaha AR. New Recommendations for Extent of Thyroidectomy and Active Surveillance for the Treatment of Differentiated Thyroid Cancer. JAMA Otolaryngol Head Neck Surg (2016) 142:625-6. doi: 10.1001/jamaoto.2016.0980

49. Ferris RL, Nikiforov Y, Terris D, Seethala RR, Ridge JA, Angelos P, et al. AHNS Series: Do you know your guidelines? AHNS Endocrine Section Consensus Statement: State-of-the-art thyroid surgical recommendations in the era of noninvasive follicular thyroid neoplasm with papillary-like nuclear features. Head Neck (2018) 40:1881-8. doi: 10.1002/hed.25141

50. Wang TS, Sosa JA. Thyroid surgery for differentiated thyroid cancer - recent advances and future directions. Nat Rev Endocrinol (2018) 14:670-83. doi: 10.1038/s41574-018-0080-7

51. Almquist M, Muth A. Surgical management of cytologically indeterminate thyroid nodules. Gland Surg (2019) 8:S105-11. doi: 10.21037/gs.2019.01.03

52. Vora A, Holt S, Haque W, Lingvay I. Long-Term Outcomes of Thyroid Nodule AFIRMA GEC Testing and Literature Review: An Institutional Experience. Otolaryngol Head Neck Surg (2020) 162(5):634-40. doi: 10.1177/ 0194599820911718

53. Nicholson KJ, Roberts MS, McCoy KL, Carty SE, Yip L. Molecular Testing Versus Diagnostic Lobectomy in Bethesda III/IV Thyroid Nodules: A CostEffectiveness Analysis. Thyroid (2019) 29:1237-43. doi: 10.1089/thy. 2018.0779

54. Labourier E. Utility and cost-effectiveness of molecular testing in thyroid nodules with indeterminate cytology. Clin Endocrinol (Oxf) (2016) 85:624-31. doi: $10.1111 /$ cen.13096

55. Najafzadeh M, Marra CA, Lynd LD, Wiseman SM. Cost-effectiveness of using a molecular diagnostic test to improve preoperative diagnosis of thyroid cancer. Value Health (2012) 15:1005-13. doi: 10.1016/j.jval. 2012.06.017

56. Zanocco KA, Wang MM, Yeh MW, Livhits MJ. Selective use of Molecular Testing Based on Sonographic Features of Cytologically Indeterminate Thyroid Nodules: A Decision Analysis. World J Surg (2020) 44:393-401. doi: 10.1007/s00268-019-05177-7

57. Fazeli SR, Zehr B, Amraei R, Toraldo G, Guan H, Kindelberger D, et al. ThyroSeq v2 Testing: Impact on Cytologic Diagnosis, Management, and Cost of Care in Patients with Thyroid Nodule. Thyroid (2020). doi: 10.1089/ thy.2019.0191

58. Shapiro S, Pharaon M, Kellermeyer B. Cost-effectiveness of Gene Expression Classifier Testing of Indeterminate Thyroid Nodules Utilizing a Real Cohort Comparator. Otolaryngol Head Neck Surg (2017) 157:596-601. doi: 10.1177/ 0194599817725709

59. Balentine CJ, Vanness DJ, Schneider DF. Cost-effectiveness of lobectomy versus genetic testing (Afirma(R)) for indeterminate thyroid nodules: Considering the costs of surveillance. Surgery (2018) 163:88-96. doi: 10.1016/j.surg.2017.10.004

60. Lin JF, Jonker PKC, Cunich M, Sidhu SB, Delbridge LW, Glover AR, et al. Surgery alone for papillary thyroid microcarcinoma is less costly and more effective than long term active surveillance. Surgery (2020) 167:110-6. doi: 10.1016/j.surg.2019.05.078

61. Giorgenon TMV, Carrijo FT, Arruda MA, Cerqueira TLO, Barreto HR, Cabral JB, et al. Preoperative detection of TERT promoter and BRAFV600E mutations in papillary thyroid carcinoma in high-risk thyroid nodules. Arch Endocrinol Metab (2019) 63:107-12. doi: 10.20945/23593997000000116

62. Fussey JM, Vaidya B, Kim D, Clark J, Ellard S, Smith JA. The role of molecular genetics in the clinical management of sporadic medullary thyroid carcinoma: A systematic review. Clin Endocrinol (Oxf) (2019) 91:697-707. doi: 10.1111/ cen. 14060 
63. Schlumberger M, Tahara M, Wirth LJ, Robinson B, Brose MS, Elisei R, et al. Lenvatinib versus placebo in radioiodine-refractory thyroid cancer. $N$ Engl $J$ Med (2015) 372:621-30. doi: 10.1056/NEJMoa1406470

64. Brose MS, Nutting CM, Jarzab B, Elisei R, Siena S, Bastholt L, et al. Sorafenib in radioactive iodine-refractory, locally advanced or metastatic differentiated thyroid cancer: a randomised, double-blind, phase 3 trial. Lancet (2014) 384:319-28. doi: 10.1016/S0140-6736(14)60421-9

65. McKelvey BA, Umbricht CB, Zeiger MA. Telomerase Reverse Transcriptase (TERT) Regulation in Thyroid Cancer: A Review. Front Endocrinol (Lausanne) (2020) 11:485. doi: 10.3389/fendo.2020.00485
Conflict of Interest: The authors declare that the research was conducted in the absence of any commercial or financial relationships that could be construed as a potential conflict of interest.

Copyright (c) 2020 Khan and Zeiger. This is an open-access article distributed under the terms of the Creative Commons Attribution License (CC BY). The use, distribution or reproduction in other forums is permitted, provided the original author(s) and the copyright owner(s) are credited and that the original publication in this journal is cited, in accordance with accepted academic practice. No use, distribution or reproduction is permitted which does not comply with these terms. 